\title{
The Microcomputer ApPlication in Physical Principles DEMONSTRATION MODEL DESIGN
}

\author{
Tomas Sysala, Petr Neumann, Karel Mikus \\ Faculty of applied informatics, Tomas Bata Univerzity in Zlin, Nad Stranemi 4511, Zlin 76005, Czech Republic
}

\begin{abstract}
The article describes a design of a microcomputer system which is realized in the educational scale model control for physical principles demonstration. That particular design project was a part of the educational facility complex project called Experimentarium aiming at basic school and high school students. The article introduces two racing car models controlled by a microcomputer. The first model set demonstrates the speed and acceleration calculation based on a real time measurement. That calculation result can be compared with results obtained during a running man experiment. The second car model set demonstrates a downforce keeping the car riding the ceiling with wheels upside down. The microcomputer control system is based on microprocessors by Atmel, and the system is described in details including illustrative pictures, schematics and graphs.
\end{abstract}

Keywords: microcomputers; education; models; physical laws
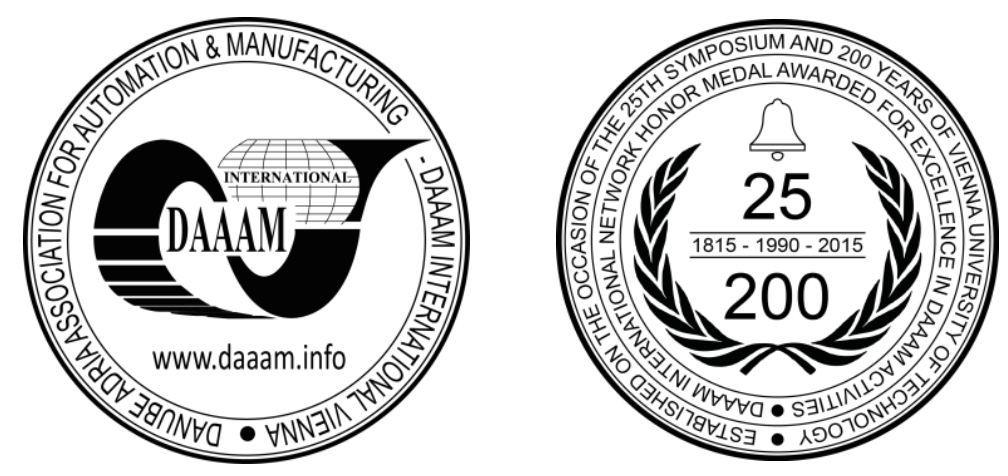

This Publication has to be referred as: Sysala, T[omas]; Neumann, P[etr] \& Mikus, K[arel] (2016). The Microcomputer Application in Physical Principles Demonstration Model Design, Proceedings of the 26th DAAAM International Symposium, pp.0125-0132, B. Katalinic (Ed.), Published by DAAAM International, ISBN 978-3-90273407-5, ISSN 1726-9679, Vienna, Austria DOI:10.2507/26th.daaam.proceedings.018 


\section{Introduction}

The teaching at basic schools and at high schools is carried out predominantly from the theoretical point of view nowadays so that practical accompanying illustrations and so called real hands-on the taught topics are missing. That is why the project designated "Experimentarium - The Centre for Education in Natural and Technical Sciences" has been established in Otrokovice city near Zlin in the Czech Republic.

Basic school pupils and high school students have an excellent opportunity to visit that Experimentarium facility to verify their gained knowledge either by only playing with demonstration gadgets or by similar procedures which are used in high school and university laboratories.

All demonstration models are installed in four floor building. Interested pupils and students can choose among many expositions aimed at, for instance mechanics, energy sources, modern technologies, chemistry, natural sciences, simple machines, electricity, magnetism, and machining.

The form of education depends on students' quantity, on their age and naturally on their interest [1]:

- A specialized motivating lecture - That lecture aims at science and technology capabilities demonstration. It also tries to motivate students to reflecting, to work in a self-reliant way, to look for particular task or theme ways of apprehension.

- LARP Activity - Live Action Role Play Activity educational form takes advantage of performed stories to induce a mood of exploration, experiment and research process to move students to problem and situation solving.

- $\quad$ Specialized movie 3D projection - That specialized movie projection takes place in a 3D cinema facility.

- The chosen exposition guided tour - The individual expositions are arranged and equipped according to the visitors' age bracket.

- Specialized educational excursion - That activity is aimed at the particular educational segment, and it represents a further knowledge completion by the practical observation of various technological, physical and natural effects in reality. Specialized excursion visits of significant companies, technical monuments, technical and natural piece of work is organized for young explorers.

- The own work presentation - Pupils fulfil various educational and cognitive tasks in course of their Experimentarium activities. After completing other activities of the shared tuition, basic school pupils get together to present their long-term work results. [1]

One exposition already mentioned above is Mechanics where two models this paper is describing are embodied in. Both models were designed and developed with respect to both hardware and software requirements, and they belong to experiments in mechanics and in aerodynamics.

First experiment demonstrates a slot car speed measurement and acceleration calculation. The slot car track has been manufactured exclusively for that purpose. As one of the Experimentarium topic deals with human body, the slot car track department has been extended with a running track. It is possible to measure a start-up reaction and elapsed time for 8 kilometers distance on both tracks. Tracks are equipped with numerous sensors elapsed time measurement in individual track segments. Those sensors make possible to calculate and to display graphically speed vs. time and acceleration vs. time plots. The whole track set is controlled by a computer communicating with microcomputers. They take care for that real time measured values plotting. There is possible to export measured data for students to be able to process them individually afterwards.

The next experiment demonstrates aerodynamics phenomena like downforce and ground effect related to the car bodywork design. The experiment goal is to show that the proper bodywork shape design can ensure the downforce exceeding the car model mass. The track is fixed on the wall, and it is oval shaped. A car model has to travel two and half meters in upside down position on that track. The oval shaped track has been chosen on purpose to show more illustratively that the car is keeping on track because of downforce and not because of centripetal or centrifugal force like people are often assuming incorrectly. All results are continuously fed on an alphanumeric LCD display.

\section{The project goals}

As already mentioned above, the project results should predominantly aim at equipment for children education development and realisation. That is why among main project goals are following requirements:

- Simplicity (comprehensibility) - Everybody should immediately understand the model educational message.

- $\quad$ Effortless controllability

- Endurance - Unlike adults, children have a different approach to exploration.

- Costs - That educational park had a limited budget. 


\section{The Employed integrated circuits}

Both models incorporate a mechanical design and controlling electronics for car models. Our center is for long time engaged in the development of microcomputer control systems [12]. Therefore the electronics is based on integrated circuits with microcomputer kernel. Those microcomputers can optionally communicate with a master computer for more illustrative data transfer visualization.

\subsection{Microprocessor Atmega128}

That processor belongs to the Atmel AVR Mega 8 bits microprocessors family with RISC architecture. That RISC microcontroller (RMCU) is very popular among the students, teachers, amateurs, engineers, scientists and hobbyists for building electronics projects $[9,10,11]$. There are 133 one clock cycle instructions implemented. The processor performance at $16 \mathrm{MHz}$ is represented with 16 MIPS. The unit embodies 328 bit executing registers, the 128 Kbytes program store Flash memory, and a 4kBytes SRAM. There are 53 programmable input/output pins to have the use of. That processor model preference was related to that number of programmable input/output pins because the car model track needs 36 position measurement sensors to be interrogated [2].

\subsection{Microprocessor Atmega8}

The Atmega8a microprocessor has been selected because of its 8-bit architecture and because of its performance and the RAM, FLASH memory reserve adequate for serving such application. That processor has an internal oscillator with maximum cycle frequency of $8 \mathrm{MHz}$. Nevertheless, that oscillator is exploitable only for non time dependent functions because of its inaccuracy and low stability. That is why an external $16 \mathrm{MHz}$ oscillator ensuring the necessary accuracy for time measurement has been added to the system. That Atmega8a microprocessor has two pins, INT0 and INT1, designated for external interrupt [3].

\subsection{CD74HC147M circuit}

CD74HC147M circuit by TEXAS INSTRUMENTS represents a 9 logical inputs encoder that is coding those inputs in 4 outputs. The circuit supply voltage is in range between 2 volts and 6 volts. The logical one level is 3.15 volts for supply voltage 4.5 volts. The high input number reduction requirement was the reason for that circuit employment. As the 8 bit microprocessor is used, the 8 bit variable is preferred because of higher execution speed. Each track makes use of two CD74HC147M circuits for 14 sensors outputs to be encoded in an eight bit value [4].

\subsection{MAX232 circuit}

Another circuit by TEXAS INSTRUMENTS serves as a signal level converter from RS-232 communication levels to the TTL level. The applied microprocessors exploit only UART/USART communication working with a 5 volts level logic. Logical low level is represented with a 0 volts level, and the high logic level is represented with plus 5 volts voltage level. That logic differs from RS-232 interface arrangement because there the logic low level is represented with -15 volts voltage level, and the high logic level is represented with +15 volts voltage level. There is a voltage incompatibility thus. The MAX232 circuit embodies a voltage multiplier which increases the +5 volts of supply voltage to the +8.5 volts level and the level inverter produces the -8.5 volts level then. The MAX232 circuit contents two TTL/RS232 converters and two RS232/TTL converters [5].

\subsection{FT231X circuit}

This circuit serves as a bidirectional communication port converter between USB and UART which creates a virtual serial port at the computer's side. That arrangement is compatible with USN 1.1 and higher versions, and it is supported by many operational systems like MS Windows, Max OS-X, Linux and Android. That circuit provides besides of basic RS232 input/output 9 pins version support further 4 input/output pins which can be assigned one of 20 accessible functions to. The other variant of communication is without virtual serial PC port just like with a standard USB port device. That circuit has a wide range of application at portable devices and everywhere microcomputers do not have the hardware USB port implementation [6].

\section{The speed and acceleration demonstration track model}

The track composes both from two car models speed measurement section and from a section for running man speed measurement. User starts the computer application program for the relevant experiment. The measurement experiment start signalization is ensured with a two colour light tower incorporating also an acoustic signal source. The car model motion is controlled via two push buttons which are starting the car engine energy supply and setting to move. The track is equipped with a protection against an untimely experiment initiation what means that there is not 
possible to switch on the energy supply until the releasing start signalization. After completing the experiment, the measured data are automatically sent to the computer where they are processed and the result is displayed.

\subsection{Design}

The basic construction material is wood and $18 \mathrm{~mm}$ chipboard. The construction is of an L-shape profile to arrange for both the track support and storage space together with seating bank. The track length is 12 meters which only 8 meters segment for measurement is used from. The remaining 4 meters segment is used as a breaking area for car models. The track surface which serves as road is fabricated from MDF (Medium Density Fibreboards) material. There are two grooves milled in that MDF layer to guide the car model along the track. The car model position sensors are also built in that MDF layer. The two colour light tower with acoustic signalization is also fixed to the track.

\subsection{The measurement method}

There are 28 sensors for elapsed time measurement allocated along the track, 14 sensors for each track. The allocation along the 8 meters track segment is illustrated in the Fig.1. As you can see in Fig.1, the sensors allocation is not a uniform one. That is because the car model acceleration is a highest one at the beginning after start, and it decrease with the speed increase. From that reason, the sensors spacing is smaller in the first half of the track than in the second one. The modified standard size racing car models are used for the measurement so that both racing car models and car models from toy sets can be used. When the car model passes a sensor, the time referred to the measurement experiment start is recorded.

\subsection{The track extension}

The track has been extended for a runner experiment data measurement like for the car models. The running track is situated collaterally with the car models track. It also has an 8 meters segment for measurement and a direct comparison of a runner and a car. As runners need a longer distance for stopping than a car model, there is the whole residual 6 meters segment used for it. These 6 meters represent the distance to the wall which is covered with a dumping mat from safety reasons. Runner is monitored with only 8 sensors because the accuracy requirements are not as high as at car models.

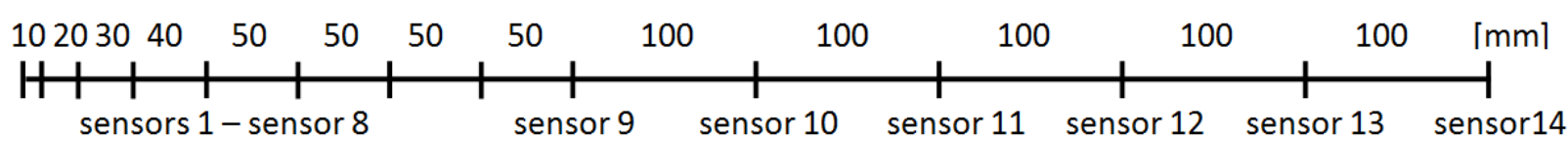

Fig. 1. The sensors allocation along the track.

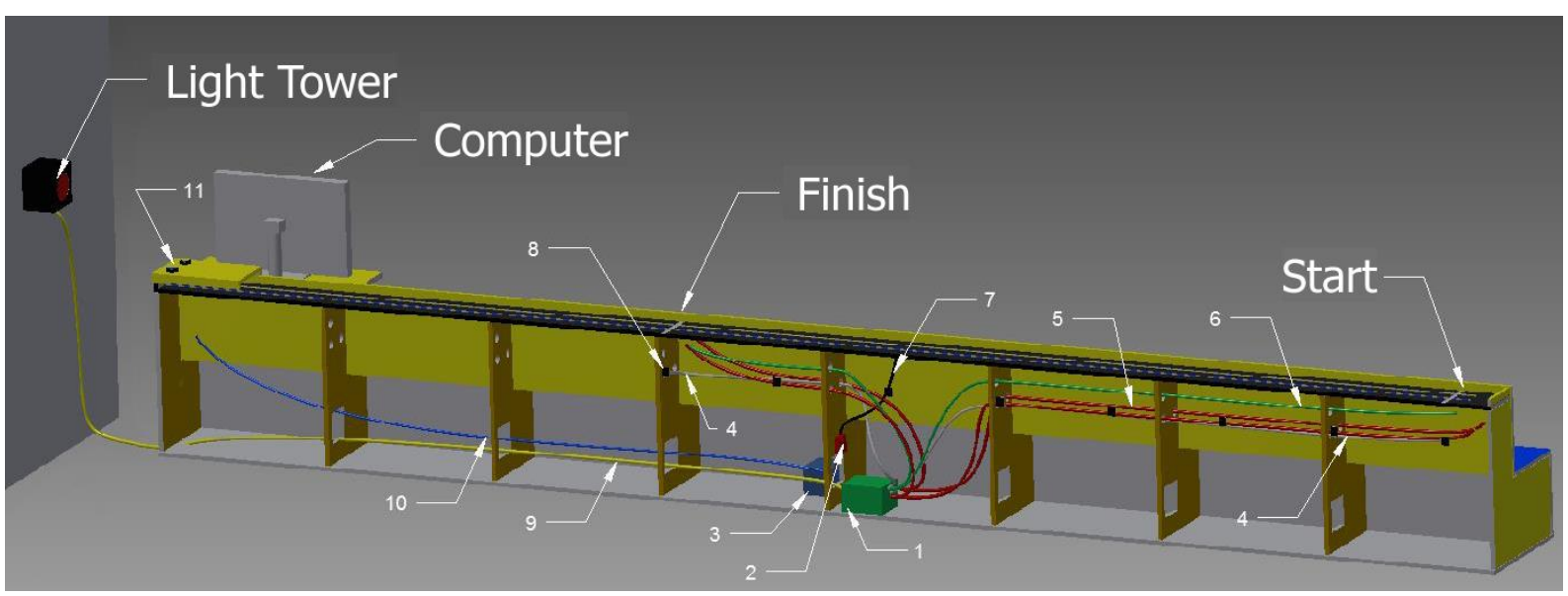

Fig. 2. The track model with electronic modules location [8].

\subsection{The model parts}

The system composes from the following functional blocks:

- Main board
- Microprocessor Atmega128
- MAX232 circuit
○ Supply voltage control 
- Sensors

- Model car track

○ Power supply

- Signal outputs

- Model car track power supply

- Model car track controllers

- Encoders

- Control electronics power supply

- Light tower

- Computer

The supporting hardware is based on the Atmega128 microprocessor by Atmel [2]. The major part is main board containing operational electronics, protection elements, a module for car track and connected sensors power supply switching. The microprocessor is interlinked with computer via RS-232 serial bus that is why the other component on the main board is the MAX232 as signal level converter. The last part situated on the main board is the control output for light tower control. Two encoders ensuring the track sensor inputs number reduction. One car track carries 14 sensors what means 14 different signals which can be encoded down to only 8 signals because only one sensor is activated at a time and the simultaneous activation of two or more sensors is a faulty state which shall be solved by software consequently. The runner track carries only 8 sensors so that no down encoding is necessary. The part for track power supply control is a circuit with starting push buttons are connected as well as power supply unit and the main board signal for power supply activation. There are three power supply units for the whole model car track and runner track system. The main board is supplied from a 5 volts output supply voltage unit. The light tower is supplied from a 12 volts source, and the car models driving power supply has a controllable voltage in the range between 3 volts and 14 volts.

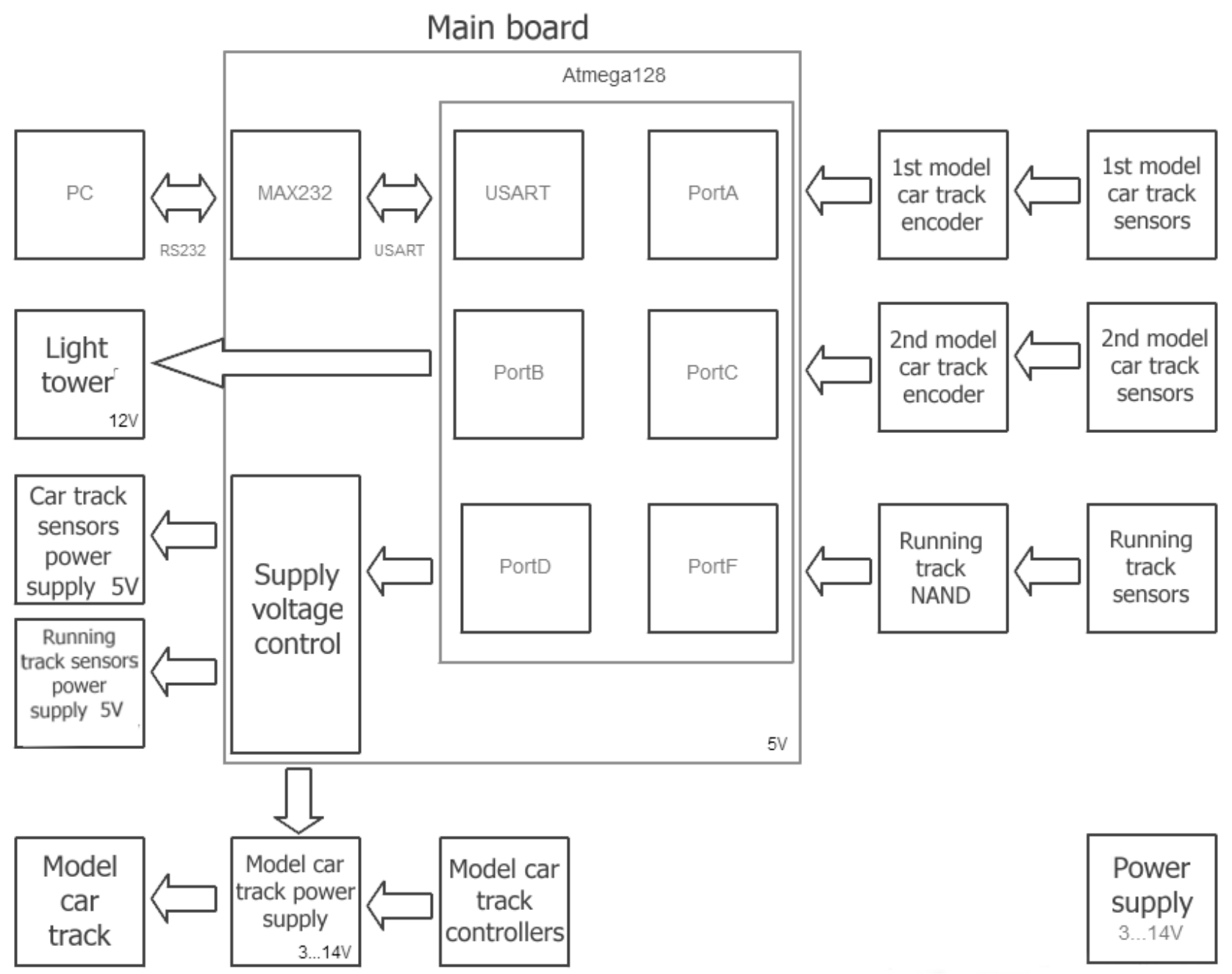

Fig. 3. The general designed system simplified illustration. 
The main board and PC communication interlink is realised via RS-232 interface. However, that interface is not a part of Atmega128 peripherals which cover only USART interface. The solution with signal lever converter circuit is described above. That MAX232 is applied in its basic functional arrangement where only capacitors C7 to C10 with a same capacity of $1 \mu \mathrm{F}$ are necessary. The input/output set for RS-232 communication is attached to CAN9 connector and the second input/output set for TTL level communication is connected to the microprocessor. As the system contents a lot of components, a block diagram represents it in a more illustrative way, see Fig. 3.

\subsection{The data evaluation}

The measured data are evaluated by the computer application program. That application program controls the whole measurement system and at the same time, it evaluates and displays those data. The time related speed charts, acceleration charts, the total elapsed time and reaction time are at disposal.

The individual charts are distinguished wit different colours. The model car track is manufactured in two colours for different track, the yellow one and the blue one. Also car models are distinguished with same colours. The chart is related to the particular model and track with the same colour. The runner is displayed in a red colour. There is possible to toggle between the Acceleration vs. Time chart and Speed vs. Time chart. It is also possible to switch off particular curves and to display only required ones. The table bellow presents the peak values measured during experiments. Pupils can calculate individual parameters from gained data by themselves offline. Data file storing in CSV format is possible for that purpose.

\section{The time related acceleration charts}

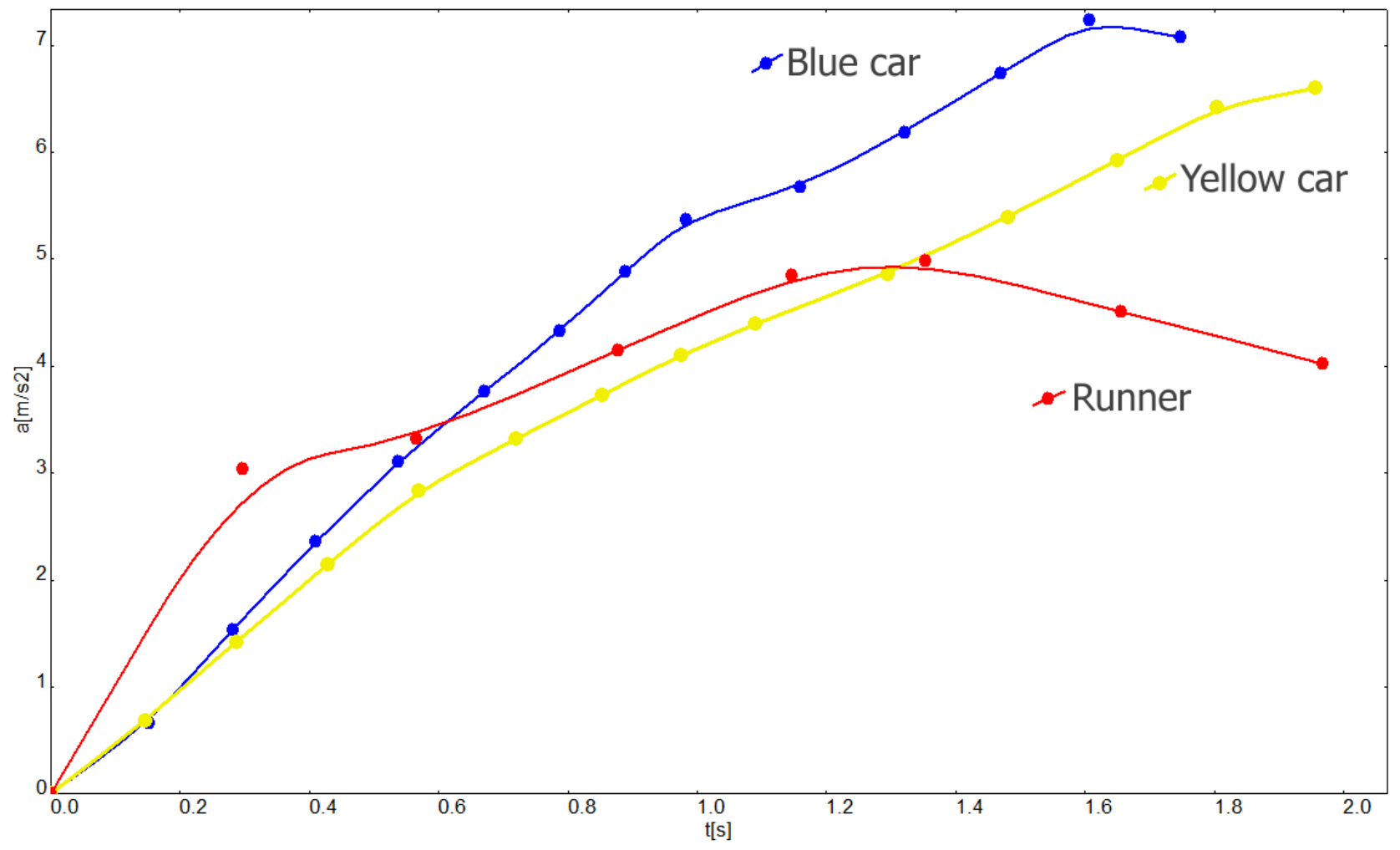

Fig. 4. The cars and runner track data evaluation results plotted in a graph [8].

\section{The downforce demonstration model}

Aerodynamics is an important physical phenomena background for aerospace and automotive industry as well as for any other areas concerned with objects that are moving in a gas environment representing a force working against that moving object. That force is called drag generally for any fluid. If the fluid is air, we use the term air drag. Racing cars, for instance, are so designed regarding to bodywork that there is a higher downforce exerted to ensure the better tyre adhesion and following that also the better car manoeuvrability. A modern Formula 1 car can exert the adhesion 3.5 times higher than its mass at the racing speed [7]. Even in reality, it would be theoretically possible that the racing car can go at a certain given speed wheels up. Nevertheless, such experiment is quite costly and dangerous. The model car demonstration of such effect is much easier to be realized if the bodywork is properly designed to ensure the relevant downforce for the car model to be able to go "wheels up the ceiling". 


\subsection{The track design}

The model car track is manufactured from the same material like the preceding track. The track base body material is chipboard, and the track surface is manufactured from an MDF board. The track contour is an oval. The oval length is 4.5 meters, and its height measures 2 meters. The track segment where the car model runs wheels up is 2.5 meters of length.

The time measurement is supported with same sensors like at the first car model track. However, only two sensors are allocated along this particular track. The first sensor measures car model elapsed time for finishing the first lap. The second sensor only detects the model car position where the model driving power supply is to be switched off for the model to stop securely in the track lower segment. Sensors are situated always prior the curve. There is possible to compare elapsed time for the upper and lower track part.

The project goal was a design of all electronics ensuring the track power supply control which is connected to the car model movement controller. The control electronics impedes the car model stopping in the track upper part. The main function of the control electronics is a possibility to adjust the lap count which is to be travelled and measured. The other control electronics task is to switch the track power supply on, and to switch it off after adjusted lap count has been elapsed to ensure the car model stop in the track lower part. All that is implemented with two push buttons and the information is presented on a four rows alphanumeric LCD display with 16 characters per row.

\subsection{The control components}

Our realized design contents many components identical with a previous model. This model incorporates the following parts:

- Main board

- Sensors

- LCD display

- Push buttons

- The track power supply relay

- Power supply 12 Volts

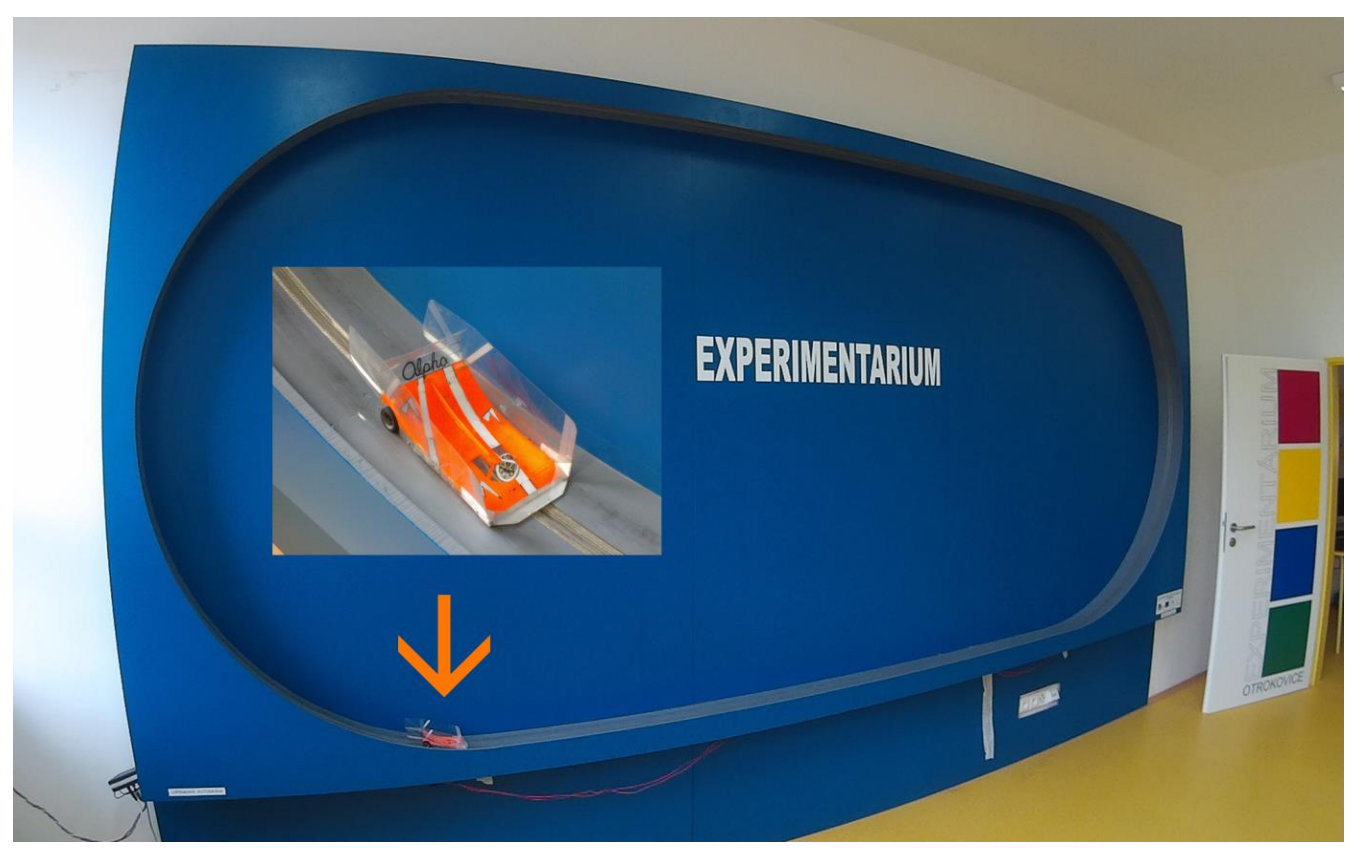

Fig. 5. The realized model general view.

\subsection{The main board}

The main board gist is Atmega8 microprocessor which execution capacity fully corresponds with the system requirements. Its clock frequency is set to $16 \mathrm{MHz}$. That clock frequency and 8bit timer application provide the time measurement accuracy of 0.001024 milliseconds. The alphameric LCD display is attached to Atmega8. It is a negative LCD design with a blue backlight source. Two push buttons in pull-down mode are connected to the microprocessor. Two PHS-7Ax connectors are interfacing signal from sensors to the microprocessor. The integrated circuit FT231x incorporated in the main board serves for an optional communication with the central computer. 


\subsection{The data evaluation}

The whole exercise concept is a demonstration one. The exercise main goal is to convince pupils that the car model can go wheels up on the ceiling. The pupil-machine communication is assisted with two push buttons and an LCD display. That display serves as an information feedback for the car model lap count adjustment, and it also serves for total elapsed lap time, or it serves for upper and lower track part travelled time alternatively. That display presents also car model speed in upper and in lower track part together with the elapsed time values.

\section{Conclusion}

The project target was to design and manufacture hardware \& software support for two educational car model tracks aimed at basic school pupils and at high school students. The project has been successfully finished as two unique systems having been serving its planned purpose since June, 2015. Facility demonstrates in reality some physical laws, equations and formulas also for other physical quantities. Those models have proven their ability to explain and illustrate selected principles related to mechanics and aerodynamics as expected.

The very important aspect of that experimental facility is the student motivation for extending permanently his knowledge gained at school. We hope in influencing the interest in technological subjects study positively because it is less and less popular unlike economics and law among young people in course of recent years.

The experience with the educational facility is bringing new inspirations and stimuli for improvement and extensions. The microcomputer based part can be modified or extended with relevant components for other experiments and models. As the basic concept has been already successfully verified in praxis, the further model variants design and development should not be so time-consuming like that pioneering project.

\section{Acknowledgements}

The authors wish to thank to the Ministry of Education, Youth and Sports of the Czech Republic (the European Regional Development Fund under the project CEBIA-Tech No. CZ.1.05/2.1.00/03.0089) for financial support.

\section{References}

[1] SPS Otrokovice, Experimentarium Otrokovice, [online] 2015, available: http://www.experimentariumotrokovice.cz/.

[2] Atmel Corporation, Atmel AVR microcontroller ATmega128 datasheet 2014, [online] 2015, available: http://www.atmel.com/Images/Atmel-8151-8-bit-AVR-ATmega128A_Datasheet.pdf.

[3] Atmel Corporation, Atmel AVR microcontroller ATmega8 L datasheet. 2013. [online] 2015, available: http://www.atmel.com/

/Images/Atmel-2486-8-bit-AVR-microcontroller-ATmega8_L_datasheet.pdf.

[4] Texas Instruments, High-speed CMOS logic encoder Cd74hc147. 2014. [online] 2015, available: http://www.ti.com/

/lit/ds/symlink/cd74hc147.pdf.

[5] Texas Instruments, Max232x dual EIA-232 drivers/receivers datasheet. 2015. [online] 2015, available: http://www.ti.com/

/lit/ds/symlink/max232.pdf.

[6] Future Technology Devices International, DS FT231X datasheet. 2013. [online] 2015, available: http://www.ftdichip.com/.

[7] Formula $1{ }^{\circledR}$ - The Official F1® Website, Understanding F1 racing - aerodynamics, [online] 2015, available: http://www.formula1.com/

/inside_f1/understanding_f1_racing/5281.html.

[8] K. Mikus, The Use of microcomputer for the construction of models for the physical laws analysis (in Czech Využití mikropočítače pro konstrukci modelů umožňujících analýzu fyzikálních zákonů), diploma thesis, Faculty of Applied Informatics, Tomas Bata University in Zlin, Zlin, 2015.

[9] J.O. Cadenas, R.S. Sherratt, D. Howlett, C.G. Guy, K.O. Lundqvist, Virtualization for Cost-Effective Teaching of Assembly Language Programming, in Education, IEEE Transactions on, vol.58, no.4, pp.282-288, Nov. 2015.

[10] A.V.Y. Phamila, R. Amutha, Energy-efficient low bit rate image compression in wavelet domain for wireless image sensor networks, in Electronics Letters, vol.51, no.11, pp.824-826, 2015.

[11] A.S. Pillai, T.B. Isha, Dynamic frequency scaling based energy consumption reduction for power-aware embedded systems - a simulation and experimental approach, Journal of Electrical Systems, vol. 10, no. 1, pp. 36-47, 2014

[12] J. Dolinay, P. Dostalek, V. Vasek, Simple and Cheap Microcontroller Kit for Students, DAAAM International Vienna, Proceedings of the 21st International DAAAM Symposium „Intelligent Manufacturing \& Automation: Focus on Interdisciplinary Solutions”, Vienna, 2010, pp. 517-519, ISBN-ISSN 978-3-901509-73-5. 